\title{
Association of SNPs in CDKN2A (P14ARF) Tumour Suppressor Gene With Endometrial Cancer in Postmenopausal Women
}

\author{
WIOLETTA WUJCICKA ${ }^{1,2}$, AGNIESZKA ZAJAC ${ }^{3}$, KRZYSZTOF SZYLLO ${ }^{3}$, \\ BEATA SMOLARZ ${ }^{4}$, HANNA ROMANOWICZ ${ }^{5}$ and GRZEGORZ STACHOWIAK ${ }^{3}$ \\ ${ }^{1}$ Scientific Laboratory of the Center of Medical Laboratory Diagnostics and Screening, \\ Polish Mother's Memorial Hospital - Research Institute, Lodz, Poland; \\ ${ }^{2}$ Department of Obstetrics, Perinatology and Gynecology, Polish Mother's Memorial Hospital - Research Institute, \\ Department of Gynecology and Obstetrics, Medical University of Lodz, Lodz, Poland; \\ ${ }^{3}$ Department of Operative Gynecology and Gynecologic Oncology, \\ Polish Mother's Memorial Hospital - Research Institute, Lodz, Poland; \\ ${ }^{4}$ Laboratory of Cancer Genetics of the Department of Clinical Pathomorphology, \\ Polish Mother's Memorial Hospital - Research Institute, Lodz, Poland; \\ ${ }^{5}$ Department of Clinical Pathomorphology, \\ Polish Mother's Memorial Hospital - Research Institute, Lodz, Poland
}

\begin{abstract}
Background/Aim: This research was aimed to evaluate the association between three selected single nucleotide polymorphisms (SNPS) within the CDKN2A (P14ARF) tumour suppressor gene and the incidence of endometrial cancer $(E C)$ in postmenopausal women. Patients and Methods: The study included 194 postmenopausal women; 144 with EC and 50 noncancer controls. Genotypes in P14ARF rs3088440, rs3731217 and rs 3731245 polymorphisms were assayed using PCR-RFLP and confirmed by sequencing. Results: Regarding the rs 3088440 polymorphism, CT, and CT-TT genotypes, were more prevalent among EC patients than in controls $(O R=5.55, p=0.023$, $O R=5.29, p=0.027$; and $O R=2.92, p=0.023$, respectively). The $T$ allele within rs3088440 was more prevalent in EC females than in controls $\left(\chi^{2}=4.7, p=0.030\right)$. Considering rs3731217, TG and TG-GG genotypes were less prevalent among EC $(O R=0.34, p=0.024$ or $p=0.023$; and $O R=0.38, p=0.035$, respectively). Conclusion: Polymorphisms in the CDKN2A gene are associated with EC in postmenopausal women.
\end{abstract}

This article is freely accessible online.

Correspondence to: Wioletta Wujcicka, Scientific Laboratory of the Center of Medical Laboratory Diagnostics and Screening, Department of Obstetrics, Perinatology and Gynecology, Polish Mother's Memorial Hospital - Research Institute, Department of Gynecology and Obstetrics, Medical University of Lodz, 281/289 Rzgowska St., 93-338 Lodz, Poland. Tel: +48 422711520, Fax: +48 422711080,e-mail:wwujcicka@yahoo.com

Key Words: CDKN2A, P14ARF, tumour suppressor gene, single nucleotide polymorphisms (SNPs), endometrial cancer.
Endometrial cancer (EC) is the fourth most common cancer among Polish women (after breast, colon, and lung cancer) responsible for $3 \%$ of cancer deaths in this population. Moreover, the incidence rate of this cancer has almost doubled in the last three decades, due to several factors, especially the increased average life expectancy of women. Hence, EC is predominantly observed in postmenopausal women in their sixth/seventh decade of life, with the highest incidence rate of $80 / 100,000$ at the end of the seventh decade (1).

P14ARF belongs to three tumour suppressor proteins, including p16INK4a and p15INK4b encoded by the $C D K N 2 A$ gene, genetic changes of which may cause cellular proliferation and tumour growth $(2,3)$. It has been shown that p14ARF influenced the course of cell cycle by activating p53 and inhibiting MDM2 expression thus leading to cell cycle arrest in $\mathrm{G}_{1}$ and $\mathrm{G}_{2} / \mathrm{M}$ phases $(4,5)$. Altered expression of p14ARF, either decreased or increased, has been found in various human tumours (5-8). Considering EC, tumor heterogeneity in CDKN2A protein expression between four different cores of primary tumours, has been reported as significantly more prevalent among samples with a higher stage of the disease (9). In another study, $C D K N 2 A$ tumour suppressor gene was included in a panel of seven immunohistochemical markers [ER, CDKN2A (p16), TP53, VIM, PTEN, PGR, and IGF2BP3] to differentiate endometrioid carcinoma in FIGO grade 3 from serous carcinoma, based on immunohistochemical qualitative assays performed by tissue microarrays (10). Moreover, moderate immunohistochemical expression of p14 has been observed in endometrioid endometrial carcinoma, while total lack has been found in endometrial hyperplasias without atypia, at the 


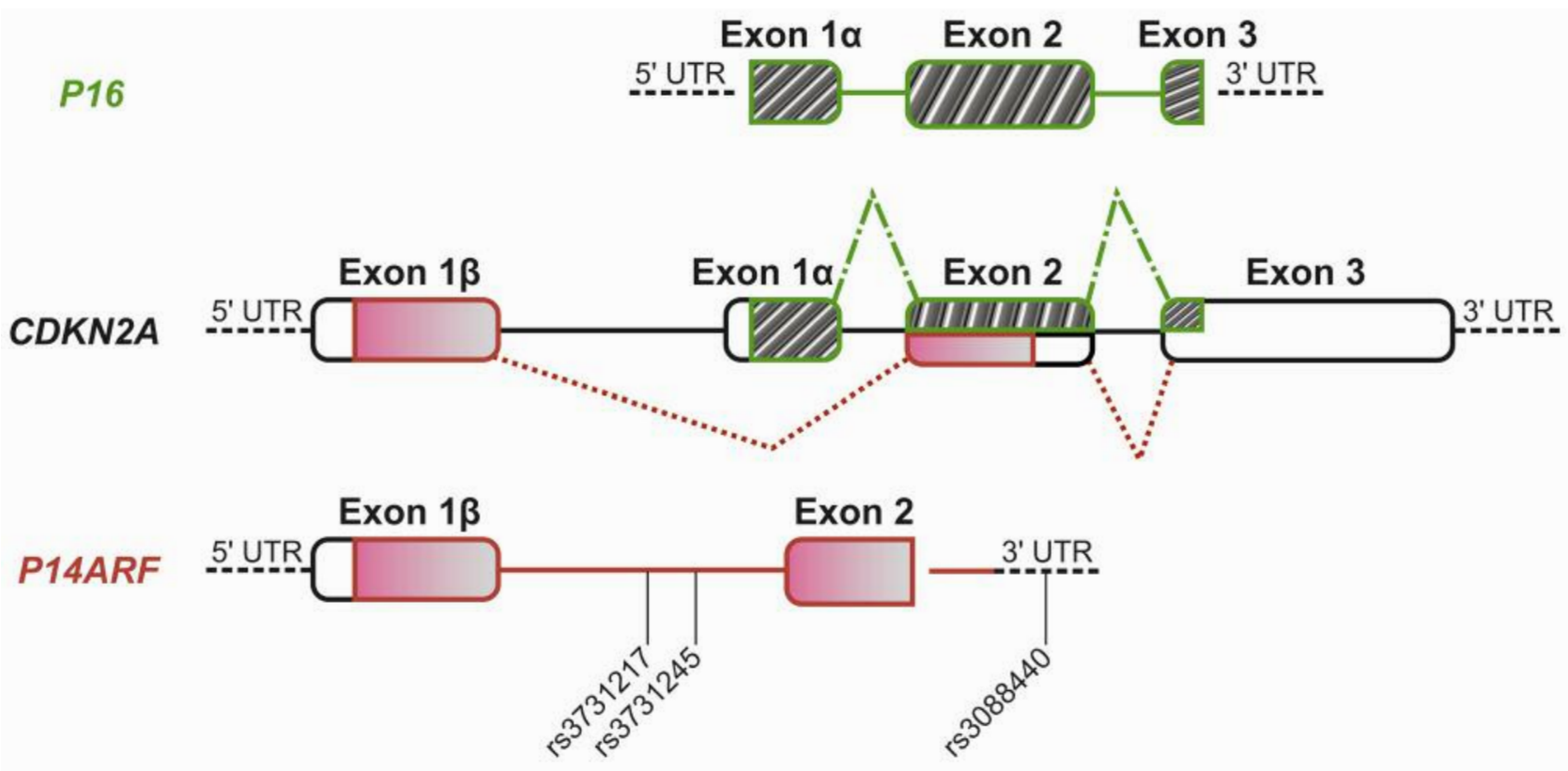

Figure 1. The structure of CDKN2A tumour suppressor gene and its alternatively spliced variants, P14ARF and P16. The location of three single nucleotide polymorphisms (SNPs), selected for the current research, is illustrated in the P14ARF gene. The alternative splicing sites are depicted with dotted red and green lines for p14ARF and p16 transcripts, respectively. UTR: the untranslated region.

nuclear level (11). Mutations in PTEN and KRAS, as well as microsatellite instability have, so far, been related to oestrogen-related, type I EC, while mutations in TP53, HER2 and $P 16$ have been associated with type II EC, unrelated to oestrogen (12).

So far, distinct single nucleotide polymorphisms (SNPs) in $C D K N 2 A(P 14 A R F)$ have been correlated with various tumours, like acute lymphoblastic leukaemia (ALL), nasopharyngeal carcinoma, medullary thyroid carcinoma, oropharyngeal cancer, oesophageal squamous cell carcinoma (ESCC), or salivary gland carcinoma (13-18). The rs3088440 polymorphism, located in the 3' UTR region of $C D K N 2 A$, has been shown to be important in the susceptibility to and for the prognosis of several cancers, including HPV16positive oropharynx cancer, melanoma, or squamous cell carcinoma of the head and neck (SCCHN) $(14,17,19)$. Among patients with paediatric B-cell precursor ALL (BCPALL), rs3731217 SNP in intron 1 of $C D K N 2 A$, has been suggested to influence the risk of cancer, by regulating alternative splicing of $C D K N 2 A$, possibly associated with the translation of p16 and p14ARF tumour suppressors (Figure 1) (20). It is noteworthy that TGA/CAG diplotypes and TGA/TAG variants for rs3731217, rs3731245, and rs3088440 SNPs, have been proposed to possibly be associated with a decreased and an increased risk of chronic benzene poisoning, respectively (21). Our previous study, performed in postmenopausal women with EC, has shown the joint effect of MDM2 SNP309, TP53 SNP rs1042522, as well as of the three polymorphisms of P14ARF in the occurrence of the cancer (22). Based on the reported changes in the protein levels of p14ARF tumour suppressor, involved in EC, as well as previous research on the functional role of the three SNPs, rs3088440, rs3731217 or rs3731245, residing within $P 14 A R F$ gene, a further study seems to be justified and needed regarding the contribution of the presented polymorphisms to EC. In that context, the goal of the current study was to evaluate the relationship between the three selected SNPs and the risk for EC in a population of postmenopausal women.

\section{Patients and Methods}

This retrospective study included 194 women; 144 with EC and 50 non-cancer control individuals (Table I). The females qualified for the study were patients of the Department of Gynaecology and Oncological Gynaecology at the Polish Mother's Memorial Hospital - Research Institute in Lodz, between December 1997 and August 2009. The qualified women were between 28 and 88 years old (the mean age: 59.1 years). The mean age of the females with EC was $61.24 \pm 9.01$ years and that of the control individuals 53.06 \pm 4.75 years. Some additional clinical data of the patients in the studied group are presented in Table I. The ECs of the qualified patients were staged, according to the criteria of the International Federation of Gynaecology and Obstetrics (FIGO), and the tumour specimens were obtained by a dilation and curettage $(D \& C)$ procedure, picking up some mucous membrane from the uterine cavity. Normal 
Table I. Characteristics of the examined women with endometrial cancer and of non-cancer controls.

\begin{tabular}{|c|c|c|c|}
\hline Characteristics & $\begin{array}{c}\text { Females with } \\
\text { endometrial cancer }\end{array}$ & $\begin{array}{l}\text { Non-cancer } \\
\text { controls }\end{array}$ & $p$-Value \\
\hline $\begin{array}{l}\text { Examined } \\
\text { women; } \mathrm{n}(\%)\end{array}$ & $144(74.2)$ & $50(25.8)$ & \\
\hline $\begin{array}{l}\text { Mean age } \pm \text { SD } \\
\text { (years) }\end{array}$ & $61.24 \pm 9.01$ & $53.06 \pm 4.75$ & \\
\hline $\begin{array}{l}\text { Diabetes } \\
\text { mellitus (\%) }\end{array}$ & 27/144 (19.0) & $0 / 48(0.0)$ & 0.001 \\
\hline $\begin{array}{l}\text { Arterial } \\
\text { hypertension (\%) }\end{array}$ & $76 / 144(52.8)$ & $16 / 48(33.3)$ & 0.020 \\
\hline \multicolumn{4}{|l|}{ BMI } \\
\hline Mean \pm SD $\left(\mathrm{kg} / \mathrm{m}^{2}\right)$ & $30.25 \pm 6.25$ & $27.43 \pm 5.17$ & \\
\hline$\leq 24.99(\%)$ & 30/137 (21.9) & $17 / 48(35.4)$ & 0.014 \\
\hline $25-29.99(\%)$ & 40/137 (29.2) & $19 / 48(39.6)$ & \\
\hline$\geq 30(\%)$ & 67/137 (48.9) & $12 / 48(25.0)$ & \\
\hline \multicolumn{4}{|l|}{ MHT } \\
\hline Yes $(\%)$ & $13 / 65(20.0)$ & 9/47 (19.1) & 0.911 \\
\hline No $(\%)$ & $52 / 65(80.0)$ & $38 / 47(80.9)$ & \\
\hline \multicolumn{4}{|l|}{ FIGO grade } \\
\hline G1 (\%) & $63 / 113(55.8)$ & & \\
\hline $\mathrm{G} 2(\%)$ & $46 / 113(40.7)$ & & \\
\hline G3 $(\%)$ & $12 / 113(10.6)$ & & \\
\hline \multicolumn{4}{|l|}{ FIGO stage } \\
\hline $\mathrm{I}(\%)$ & $86 / 131(65.6)$ & & \\
\hline II $(\%)$ & 23/131 (17.6) & & \\
\hline III $(\%)$ & $22 / 131(16.8)$ & & \\
\hline \multicolumn{4}{|l|}{$\begin{array}{l}\text { Endometrial } \\
\text { thickness }\end{array}$} \\
\hline Mean \pm SD $(\mathrm{mm})$ & $14.64 \pm 13.02$ & $6.23 \pm 2.99$ & \\
\hline$>5 \mathrm{~mm}(\%)$ & $107 / 127(84.3)$ & $23 / 45(51.1)$ & $9 \times 10^{-6}$ \\
\hline
\end{tabular}

$\mathrm{n}$ : Number of examined women; SD: standard deviation; BMI: body mass index; MHT: menopausal hormone therapy; FIGO: the International Federation of Gynaecology and Obstetrics; Pearson's Chi-squared test.

endometrial tissues of the non-cancer controls were used as control samples, obtained also by curettage, performed for medical indications (in patients with bleeding from the genital tract or prepared for gynaecological procedures). The study was approved (approval number: 2/2016) by the Research Ethics Committee at the Polish Mother's Memorial Hospital - Research Institute. All the samples, previously collected for diagnostic purposes, were anonymised in the reported project. Informed consent forms were signed by the qualified women, the consent procedure had first been accepted by the Research Ethics Committee.

DNA extraction. Genomic DNA specimens were extracted from stored, paraffin-embedded sections of cancerous and healthy endometrial tissues, using a Syngen FFPE DNA Micro Kit (Syngen Biotech, Wroclaw, Poland). The obtained DNA was diluted in $100 \mu \mathrm{l}$ elution buffer and stored at $-20^{\circ} \mathrm{C}$ until further genetic analyses.

Genotyping of SNPs, located within CDKN2A (P14ARF) gene. The genotypes, of the polymorphisms rs3088440, rs3731217 and rs3731245 located within CDKN2A (P14ARF), were determined, using self-designed nested PCR-RFLP assays. The primer sequences and conditions of the PCR assays are presented in Table II. The external primers were designed, using the PerlPrimer v1.1.21 software, and the internal primers were obtained from the literature $(15,19,22-24)$. Nested PCR products were resolved on $1 \%$ agarose gels, stained with ethidium bromide, and then digested overnight with HaeIII (EURx, Gdansk, Poland), and MvaI (Thermo Fisher Scientific, Waltham, MA, USA) endonucleases to determine genotypes of rs3088440 and rs3731217, as well as of rs3731245 polymorphisms, respectively. Genotypic profiles were estimated from the length of the achieved restriction fragments, resolved on $2 \%$ agarose gels (Figure 2, Table III). Several specimens for rs3731217 (four EC cases) and rs3731245 (three ECs and one control case) polymorphisms were excluded from further analysis due to the lack of digested fragments, observed on agarose gels. The selected PCR products, representative of distinct genotypes in the studied SNPs, were then sequenced by the Sanger method at the Genomed Joint-Stock Company (Warsaw, Poland), to confirm nested PCR-RFLP outcomes. The sequencing process was performed for nine CC homozygotes, twelve CT heterozygotes and two TT homozygotes in rs3088440 SNP, for eleven TT homozygotes, and five TG heterozygotes in rs 3731217 polymorphism, as well as for one GA heterozygote and fifteen GG homozygotes in rs 3731245 polymorphism of the P14ARF gene. The sequences of obtained chromatograms were analysed by the Sequence Scanner 1.0 (Applied Biosystems, Waltham, MA, USA) program.

Statistical analysis. The distribution of obtained clinical data, as well as of single genotypes, alleles, and haplotypes was estimated by descriptive statistics, using the SNPStats software (25). Genotypes in the analysed polymorphisms were determined by the Hardy-Weinberg $(\mathrm{H}-\mathrm{W})$ equilibrium and linkage disequilibrium (LD). Relationships were calculated between the clinical data and genotypes of the polymorphisms and the occurrence of EC among the examined women, using the cross-tabulation and the Pearson's Chi-square test. A logistic regression model was employed to define the genetic models of inheritance, including codominant, dominant, recessive and overdominant. The undertaken attempts identified optimal inheritance models of the genetic changes of the studied polymorphisms, typical for EC in the examined patients. The multiple-SNP analyses of haplotypes in PI4ARF SNPs were performed by the Expectation Maximization (EM) algorithm. The results were acknowledged as statistically significant at the significance level of $p \leq 0.050$. The statistical analysis was, in part, supported by the NCSS 2004 software.

\section{Results}

Hardy-Weinberg equilibrium, linkage disequilibrium. HardyWeinberg $(\mathrm{H}-\mathrm{W})$ equilibrium was preserved in $C D K N 2 \mathrm{~A}$ $(P 14 A R F)$ rs3731217 and rs3731245 polymorphisms in all of the examined female patients $(p>0.050)$, while it was not found in rs3088440 SNP among the analyzed patients $(p \leq 0.050)$. Polymorphisms were observed in the linkage disequilibrium (LD), found between the analyzed groups of women $(p \leq 0.050)$.

Distribution of genotypes within CDKN2A (P14ARF) gene polymorphisms. In the females with endometrial cancer, the CC, CT and TT genotypes within P14ARF rs3088440 SNP 
in vivo $34: 943-951(2020)$

Table II. Conditions of nested PCR assays for genotyping of the polymorphisms located within CDKN2A (P14ARF) gene.

\begin{tabular}{|c|c|c|c|c|c|}
\hline \multirow{2}{*}{$\begin{array}{l}\text { GenBank } \\
\text { Accession No. } \\
\text { NC_000009.12 }\end{array}$} & \multirow{2}{*}{$\begin{array}{c}\text { SNP name } \\
\text { [global MAF (\%)] } \\
\text { rs3088440 } \\
(16.99)\end{array}$} & \multicolumn{2}{|r|}{ Oligonucleotide sequences $\left(5^{\prime}-3^{\prime}\right)$} & \multirow{2}{*}{$\begin{array}{c}\begin{array}{c}\text { Annealing } \\
\text { temperature }\left({ }^{\circ} \mathrm{C}\right)\end{array} \\
55\end{array}$} & \multirow{2}{*}{$\begin{array}{c}\begin{array}{c}\text { Amplicon length } \\
\text { (bps) }\end{array} \\
356\end{array}$} \\
\hline & & External & $\begin{array}{l}\text { For: TGCTCACTCCAGAAAACTCCA } \\
\text { Rev: ATGTGCCACACATCTTTGACC }\end{array}$ & & \\
\hline & & Internal & $\begin{array}{l}\text { For: GATGTGCCACACATCTTTGACCT } \\
\text { Rev: CTACGAAAGCGGGGTGGGTTGT }\end{array}$ & 55 & 181 \\
\hline & $\begin{array}{l}\text { rs3731217 } \\
(12.54)\end{array}$ & External & $\begin{array}{l}\text { For: CAGGTGAAGAATGTGATTTGG } \\
\text { Rev: CAAGTGGAAGGTACAATGGAG }\end{array}$ & 55 & 590 \\
\hline & & Internal & $\begin{array}{l}\text { For: AAAAGGGGGACAACCATTCTC } \\
\text { Rev: CCCCTCTCAAATATGCTGTCC }\end{array}$ & 55 & 280 \\
\hline & $\begin{array}{l}\text { rs3731245 } \\
\quad(4.97)\end{array}$ & External & $\begin{array}{l}\text { For: ACTCTCAAATCATAAACCTGGG } \\
\text { Rev: CCCAATGTCTATGTCCTAATCCTC }\end{array}$ & 55 & 440 \\
\hline & & Internal & $\begin{array}{l}\text { For: CAAAAATGGGTCCACAAGGTT } \\
\text { Rev: CCCAACATAACCCCAAGTGTT }\end{array}$ & 55 & 195 \\
\hline
\end{tabular}

No.: Number; SNP: single nucleotide polymorphism; MAF: minor allele frequency; bps: base pairs.

were observed in $71.5 \%(103 / 144), 18.1 \%(26 / 144)$, and $10.4 \%(15 / 144)$, respectively (Table IV). In the case of rs 3731217 , the TT, TG and GG genotypes were found in $91.4 \%(128 / 140), 7.9 \%(11 / 140)$, and $0.7 \%(1 / 140)$ of the studied patients, respectively. Considering rs 3731245 , the GG and GA genotypes were determined in $93.6 \%(132 / 141)$ and $6.4 \%(9 / 132)$ of the patients with cancer, respectively. Taking into account the non-cancer control females, the CC, CT and TT genotypes in rs3088440 polymorphism were found in $88.0 \%(44 / 50), 4.0 \%(2 / 50)$, and $8.0 \%(4 / 50)$ of the patients, respectively. Regarding rs 3731217 , the TT and TG genotypes were observed in $80.0 \%$ (40/50), and $20.0 \%$ (10/50) of the studied individuals, respectively. In the case of rs3731245, GG homozygous status was observed in all the non-cancer females. Figure 3 illustrates examples of the chromatograms for the genotypes in the analysed PI4ARF polymorphisms.

Considering the rs3088440 polymorphism, the CT heterozygous females were found to be significantly positively associated with EC, as compared to the $\mathrm{CC}$ and TT homozygous patients $(\mathrm{OR}=5.55,95 \% \mathrm{CI}=1.26-24.42$, in the codominant model, $p=0.023$, and $\mathrm{OR}=5.29,95 \% \mathrm{CI}=1.21-23.16$, in the overdominant model, $p=0.027$, Table IV). Moreover, the CT-TT genotypes were significantly more prevalent among the cancerous patients $(\mathrm{OR}=2.92,95 \% \mathrm{CI}=1.16-7.37$, in the dominant model, $p=0.023$ ). In the case of rs3731217 SNP, the TG heterozygous status was significantly less prevalent among the patients with EC, as compared to TT-GG homozygotes (OR=0.34, 95\% $\mathrm{CI}=0.14-0.87$, in the codominant model, $p=0.024$, and $95 \% \mathrm{CI}=0.13-0.86$, in the overdominant model, $p=0.023$ ). Furthermore, the dominant model showed that the TG-GG genotypes were significantly negatively associated with tumour occurrence $(\mathrm{OR}=0.38,95 \% \mathrm{CI}=0.15-0.93, p=0.035)$. Additionally, the multiple-SNP analysis showed significantly higher prevalence rates of the CTA haplotypes in the range of all the studied polymorphisms, observed among the females with EC, as compared to the non-cancer individuals $(p \leq 0.050)$. Taking into account the clinical data of the studied patients, similar prevalence rates were observed for all the analyzed genotypes in the studied women.

Allelic variants within SNPs of the P14ARF gene. Among the females with endometrial cancer, the $\mathrm{C}$ and $\mathrm{T}$ alleles within rs3088440 SNP were found with prevalence rates of $81.0 \%(232 / 288)$ and $19.0 \%(56 / 288)$, respectively (Table $\mathrm{V})$. In the case of rs3731217 polymorphism, the $\mathrm{T}$ and $\mathrm{G}$ alleles were observed with prevalence rates of $95.0 \%$ (267/280) and 5.0\% (13/280), respectively. Regarding the rs3731245 polymorphism, the prevalence rates of $\mathrm{G}$ and $\mathrm{A}$ alleles were $97.0 \%(273 / 282)$ and 3.0\% (9/282), respectively.

In the non-cancer control women, the $\mathrm{C}$ and $\mathrm{T}$ alleles within rs3088440, and the $\mathrm{T}$ and $\mathrm{G}$ alleles in rs3731217 polymorphisms were determined with prevalence rates of $90.0 \%(90 / 100)$ and $10.0 \%(10 / 100)$, respectively. In the case of rs3731245, only the $\mathrm{G}$ allele was identified in all the studied control individuals $(100.0 \%, 98 / 98)$. Regarding the rs3088440 polymorphism, the T allele was significantly more prevalent among the females with EC, as compared to the non-cancer control individuals $\left(\chi^{2}=4.7, p=0.030\right.$, Table V). In turn, the alleles in both rs3731217 and rs3731245 polymorphic sites were similarly distributed between the studied groups of women.

\section{Discussion}

Studies on correlations between p14ARF and endometrial cancer have, so far, been rather not numerous, while p14ARF is a component of the p53 pathway (p14ARF/MDM2/p53), essential for the development and progression of various 


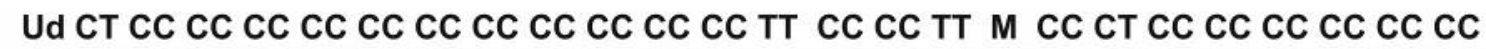
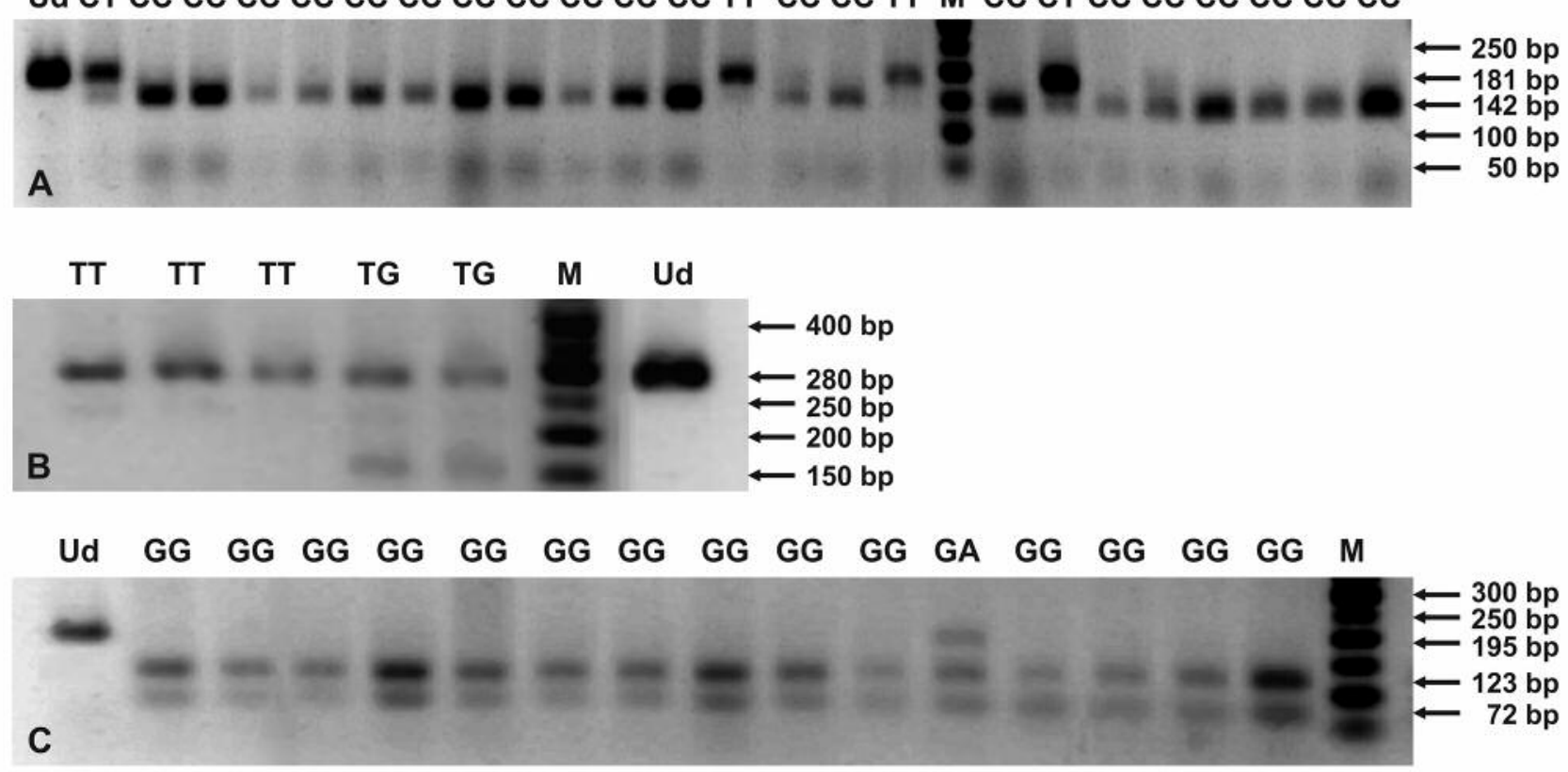

Figure 2. Nested PCR-RFLP products for P14ARF rs3088440 (A), rs3731217 (B) and rs3731245 (C) polymorphisms. The products, digested with HaeIII ( $A$ and $C$ ) or MvaI (B) endonucleases, were resolved in $2 \%$ agarose gels and stained with ethidium bromide. The numbers on the right side of the pictures correspond to the lentghs of separated DNA fragments. M: 50 bp DNA marker; Ud: undigested PCR product; CC, CT, GA, GG, TG, or TT: genotypes within the analyzed SNPs.

human neoplasms, including $\mathrm{EC}(4,5,22)$. Certain modulations in EC cells kinetics, possible via alterations in this pathway, [p14ARF/p53/p21(WAF1)], may result from a correlation between Sox 9 and NF-kB signalling mechanisms, as well as from the Akt status (26). Olcha et al. have observed expression of $\mathrm{p} 14 \mathrm{ARF}$ protein in more than a half of the analyzed primary EC and metastatic lesions and found it to be positively associated with the transtubal dissemination of the primary tumour (27). Expression of p14ARF has been found by Watanabe et al. to be significantly higher in G1 EC tumours than in normal endometrial hyperplasias (5).

In the current study, the CT heterozygotes, as compared to $\mathrm{CC}$ and TT homozygotes, as well as the CT-TT genotypes, in the P14ARF rs3088440 SNP were found to be significantly more prevalent among the EC patients than in the controls. Moreover, the $\mathrm{T}$ allele, present within rs3088440 region, was significantly associated with the cancer phenotype. The GA and AA genotypes within the rs3088440 SNP, have been previously assumed to be correlated with an increased risk of second primary malignancy among patients with SCCHN as well (19). In another study, the $\mathrm{T}$ allele within rs3088440 has been reported to be correlated with an increased risk of melanoma (28). Considering the role of rs3088440, the $\mathrm{C}$ allele has been reported to favour the binding of c-Myb transcription factor to the transcriptional regulatory region of $C D K N 2 A$,
Table III. Restriction endonucleases and genotypic profiles obtained in PCR-RFLP assays.

\begin{tabular}{lcc}
\hline Polymorphism & Restriction enzyme & Profile (bps) \\
\hline rs3088440 & HaeIII & CC: 142,39 \\
& & CT: $181,142,39$ \\
rs3731217 & Tr: 181 \\
& & TT: 280 \\
rs3731245 & HaeIII & TG: $280,154,126$ \\
& & GG: 154,126 \\
& & AA: 195 \\
& & AG: $195,123,72$ \\
& & GG: 123,72 \\
\hline
\end{tabular}

bps: Base pairs.

possibly resulting in its repression and compromise of its normal function in cell cycle $(16,29)$. In turn, the A allele has been found to be possibly associated with an impaired binding of miR-663b to the CDKN2A 3' UTR, leading to an increased expression of $\mathrm{p} 14 / \mathrm{p} 16$ proteins $(14,30)$. Therefore, the contribution of the $\mathrm{T}$ allele to $\mathrm{EC}$ formation seems fairly plausible through the altered binding of transcription factors to the transcriptional regulatory site of $C D K N 2 A$.

In case of rs3731217 SNP, TG heterozygotes, as well as the TG-GG genotypes, were found to be significantly less 
Table IV. Relationships between genotypes in P14ARF single nucleotide polymorphisms and the occurrence of endometrial cancer in the patients.

\begin{tabular}{|c|c|c|c|c|c|c|}
\hline \multirow[b]{2}{*}{ Gene polymorphism } & \multirow[b]{2}{*}{ Genetic model } & \multirow[b]{2}{*}{ Genotype } & \multicolumn{2}{|c|}{ Genotype prevalence rates; n (\%) } & \multirow[b]{2}{*}{ OR $(95 \% \mathrm{CI})$} & \multirow[b]{2}{*}{$p$-Value } \\
\hline & & & Endometrial cancer & Control individuals & & \\
\hline \multirow[t]{9}{*}{ rs 3088440} & Codominant & $\mathrm{CC}$ & $103(71.5 \%)$ & $44(88.0 \%)$ & 1.00 & \\
\hline & & $\mathrm{CT}$ & $26(18.1 \%)$ & $2(4.0 \%)$ & $5.55(1.26-24.42)$ & 0.023 \\
\hline & & $\mathrm{TT}$ & $15(10.4 \%)$ & $4(8.0 \%)$ & $1.60(0.50-5.10)$ & 0.425 \\
\hline & Dominant & $\mathrm{CC}$ & $103(71.5 \%)$ & $44(88.0 \%)$ & 1.00 & \\
\hline & & CT-TT & $41(28.5 \%)$ & $6(12.0 \%)$ & $2.92(1.16-7.37)$ & 0.023 \\
\hline & Recessive & CC-CT & $129(89.6 \%)$ & $46(92.0 \%)$ & 1.00 & \\
\hline & & $\mathrm{TT}$ & $15(10.4 \%)$ & $4(8.0 \%)$ & $1.34(0.42-4.24)$ & 0.621 \\
\hline & Overdominant & CC-TT & $118(81.9 \%)$ & $48(96.0 \%)$ & 1.00 & \\
\hline & & $\mathrm{CT}$ & $26(18.1 \%)$ & $2(4.0 \%)$ & $5.29(1.21-23.16)$ & 0.027 \\
\hline \multirow[t]{9}{*}{ rs 3731217} & Codominant & TT & $128(91.4 \%)$ & $40(80.0 \%)$ & 1.00 & \\
\hline & & TG & $11(7.9 \%)$ & $10(20.0 \%)$ & $0.34(0.14-0.87)$ & \\
\hline & & GG & $1(0.7 \%)$ & $0(0.0 \%)$ & NA $(0.00-\mathrm{NA})$ & 0.024 \\
\hline & Dominant & $\mathrm{TT}$ & $128(91.4 \%)$ & $40(80.0 \%)$ & 1.00 & \\
\hline & & TG-GG & $12(8.6 \%)$ & $10(20.0 \%)$ & $0.38(0.15-0.93)$ & 0.035 \\
\hline & Recessive & TT-TG & $139(99.3 \%)$ & $50(100.0 \%)$ & 1.00 & \\
\hline & & GG & $1(0.7 \%)$ & $0(0.0 \%)$ & NA $(0.00-\mathrm{NA})$ & \\
\hline & Overdominant & TT-GG & $129(92.1 \%)$ & $40(80.0 \%)$ & 1.00 & \\
\hline & & TG & $11(7.9 \%)$ & $10(20.0 \%)$ & $0.34(0.13-0.86)$ & 0.023 \\
\hline \multirow[t]{2}{*}{ rs 3731245} & - & GG & $132(93.6 \%)$ & $49(100.0 \%)$ & 1.00 & \\
\hline & & GA & $9(6.4 \%)$ & $0(0.0 \%)$ & NA $(0.00-\mathrm{NA})$ & \\
\hline
\end{tabular}

n: Number of tested women; OR: odds ratio; 95\% CI: confidence interval; logistic regression model; NA: not analyzed.

prevalent among the EC patients as compared to the controls. The rs3731217 polymorphism has been previously associated with ALL in the Caucasians, and the minor G allele within the SNP was found to be protective against paediatric BCP-ALL $(18,31)$. In turn, the incidence rates of the $\mathrm{T}$ allele have been found to be similar, both among cases and controls for paediatric ALL in the Tunisian population (32). Among patients with HPV16-positive squamous cell carcinoma of the oropharynx (SCCOP), the carriers of the TT genotype have been reported to have an increased risk either for death or for the recurrence of the disease, as compared to TG or GG genotypes (17). Regarding the functional analysis of rs3731217, the minor $\mathrm{G}$ allele has been associated with an elevated expression of exon 3, encompassing the 3'-UTR of $C D K N 2 A$, resulting in higher levels of CDKN2A tumour suppressor protein (20). In the case of EC, the $\mathrm{G}$ allele of the rs3731217 polymorphic site seemed also to be protective against the cancer.

Regarding rs3731245, the polymorphism has previously been reported to be associated with cerebral infarction, a risk of chronic benzene poisoning and with the ischemic stroke subtype-small vessel disease $(21,33,34)$. Considering the functional significance of rs3731245, located within the first intron of $C D K N 2 A$ gene, it has been suggested to possibly be either in LD with other functional SNPs in the genomic region of $C D K N 2 A$ or in $\mathrm{LD}$ with an intron-based transcription enhancer or silencer, located in the first intron
Table V. Distribution of alleles in P14ARF polymorphisms.

\begin{tabular}{lcccc}
\hline & & \multicolumn{2}{c}{ No. of alleles (\%) } & \\
\cline { 2 - 4 } $\begin{array}{l}\text { Gene polymorphism } \\
\text { and alleles }\end{array}$ & $\begin{array}{c}\text { Females with } \\
\text { endometrial cancer }\end{array}$ & Controls & $p$-Value \\
\hline rs3088440 & $\mathrm{C}$ & $232(81.0)$ & $90(90.0)$ & 0.030 \\
& $\mathrm{~T}$ & $56(19.0)$ & $10(10.0)$ & \\
rs3731217 & $\mathrm{T}$ & $267(95.0)$ & $90(90.0)$ & 0.054 \\
& $\mathrm{G}$ & $13(5.0)$ & $10(10.0)$ & \\
rs3731245 & $\mathrm{G}$ & $273(97.0 \%)$ & $98(100.0 \%)$ & 0.073 \\
& $\mathrm{~A}$ & $9(3.0 \%)$ & $0(0.0 \%)$ & \\
\hline
\end{tabular}

No.: Number; Pearson's Chi-squared test.

(33). In our study, the polymorphism was observed to be in LD with both rs3088440 and rs3731217 SNPs, while an additional multiple-SNP analysis showed the CTA haplotypes of the analyzed polymorphisms to be significantly positively associated with EC occurrence. Similarly, a common involvement of all the analyzed three SNPs has been reported for the chronic benzene poisoning (21). Moreover, the A allele within rs3731245 has been suggested to create the polymorphic site to be more susceptible to binding of MDM2 and protective against degradation of p53 (21). Such a mechanism of rs3731245 SNP action seems possible for the development of EC. 

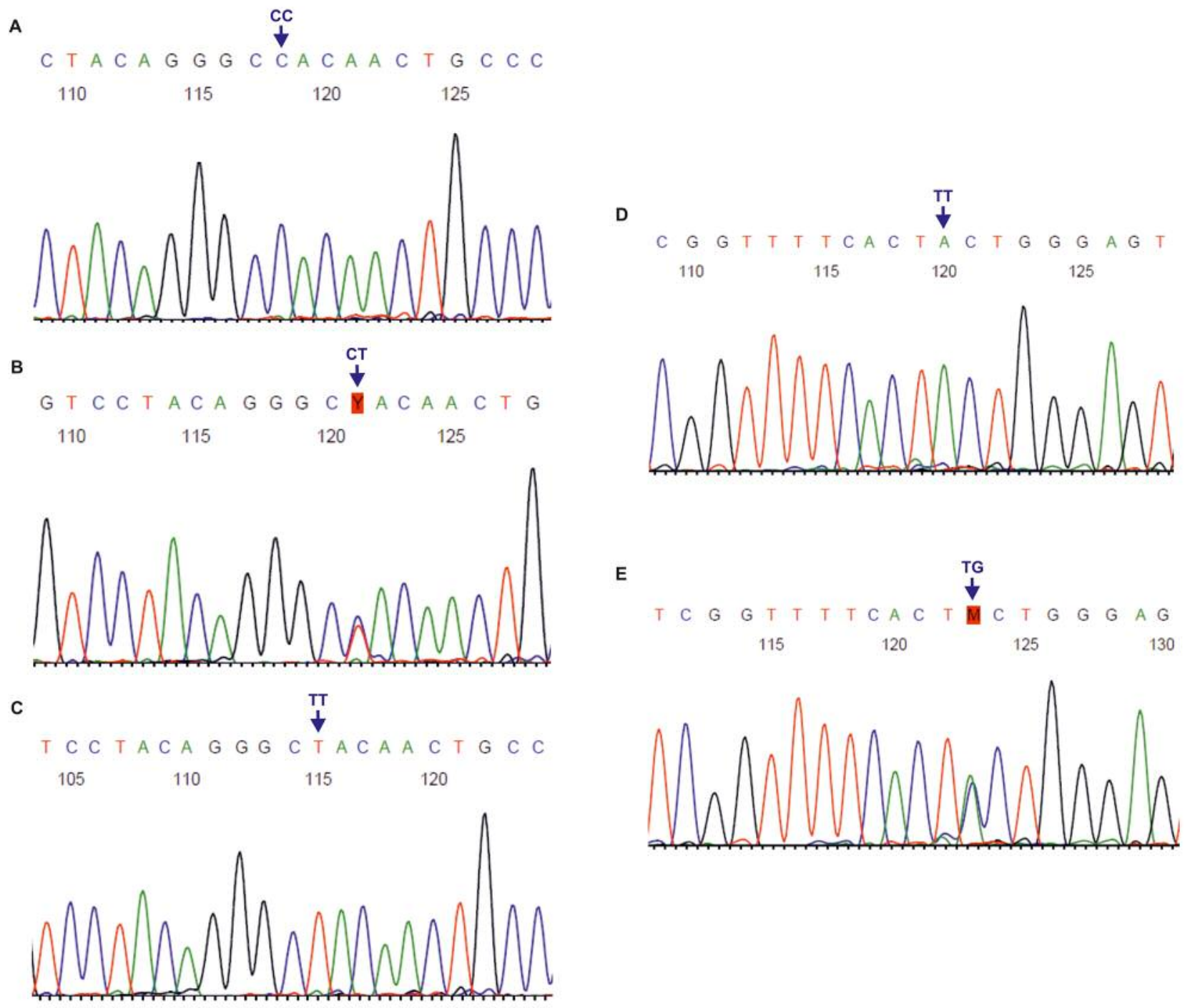

Figure 3. Chromatograms with DNA fragments, containing P14ARF rs3088440 (A-C), and rs3731217 (D, E) polymorphisms. DNA forward strands were studied for rs3088440 SNP and the reverse strands-for rs3731217 polymorphism. CC, CT, TG, or TT: genotypes in the presented SNPs.

Summing up, three $C D K N 2 A$ polymorphisms, studied in the current research project, were plausibly associated with the occurrence of EC among the postmenopausal women. Considering its functional analysis, the minor $\mathrm{T}$ allele within rs3088440 may have contributed to the cancer formation through an altered binding of transcription factors to the $C D K N 2 A$ 3' UTR region, while the minor $\mathrm{G}$ allele within rs3731217 seemed to be protective against EC. The important positive relationship between the CTA haplotypes, observed for all the studied CDKN2A SNPs and EC, may be also suggestive of rs3731245 association with the cancer.

Taking into account our previous studies, we demonstrated that the SNP309 polymorphism of the MDM2 gene is strongly associated with EC (both the GG genotype and the G allele), while the TP53 codon 72 polymorphism has been of a prognostic value and useful for the prophylaxis from EC (the Arg/Arg homozygote has been linked with an increased, while the Pro/Arg heterozygote and the Pro allele - with a decreased EC risk) (35-37). Moreover, the research about the joint effect of MDM2 SNP309, TP53 rs1042522, and the three currently described P14ARF polymorphisms on the onset of EC in postmenopausal women, concluded that MDM2 SNP309 plays a role in this cancer (22). The multiple-SNP combinations GArg-C-T-G for MDM2, TP53, and the three P14ARF polymorphisms, increased EC risk, while the T-Arg-C-T-G variants decreased risk for disease (22). Further studies seem to be justified and needed to reveal the detailed role of PI4ARF SNPs in endometrial cancer formation. 


\section{Conflicts of Interest}

The Authors have no conflicts of interest to disclose regarding this study.

\section{Authors' Contributions}

Wioletta Wujcicka: Design and performance of genetic research, data collection and management, data analysis and interpretation, manuscript writing and editing, final approval of the submitted version of manuscript; Agnieszka Zając: Conception, data collection, revising the article, final approval of the submitted version of manuscript; Krzysztof Szyłło: Data collection and management, final approval of the submitted version of manuscript; Beata Smolarz: Data collection and management, final approval of the submitted version of manuscript; Hanna Romanowicz: Data collection and management, final approval of the submitted version of manuscript; Grzegorz Stachowiak: Project development, data collection and management, interpretation of data, manuscript writing and editing, final approval of the submitted version of manuscript.

\section{Acknowledgements}

This study was funded by the Polish Ministry of Science \& Higher Education and by Polish Mother's Memorial Hospital-Research Institute (Grant No. 2016/VII/30-GW).

\section{References}

1 Endometrial Neoplasms (C54). Available at: http://onkologia. org.pl/nowotwory-trzonu-macicy-kobiet-c54/[Last accessed $16 / 01 / 2020]$

2 El-Mokadem I, Kidd T, Pratt N, Fleming S and Nabi G: Tumour suppressor gene (CDKNA2) status on chromosome 9p in resected renal tissue improves prognosis of localised kidney cancer. Oncotarget 7(45): 73045-73054, 2016. PMID: 27682877. DOI: $10.18632 /$ oncotarget.12196

3 Inoue $\mathrm{K}$ and Fry EA: Aberrant expression of p14(ARF) in human cancers: A new biomarker? Tumor Microenviron 1(2): 37-44, 2018. PMID: 29951643. DOI: 10.15761/CRR.1000145

4 Ko A, Han SY and Song J: Regulatory network of ARF in cancer development. Mol Cells 41(5): 381-389, 2018. PMID: 29665672. DOI: $10.14348 /$ molcells.2018.0100

5 Watanabe J, Nishizaki R, Jobo T, Kamata Y, Hata H, Nishimura Y, Fujisawa T, Okayasu I and Kuramoto H: Expression of tumor suppressor gene product p14ARF in endometrioid adenocarcinoma of the uterine corpus. Int J Gynecol Pathol 23(3): 234-240, 2004. PMID: 15213599. DOI: 10.1097/01.pgp.0000130050.27266.9a

6 Bai M, Yu NZ, Long F, Feng C and Wang XJ: Effects of CDKN2A (p16INK4A/p14ARF) Over-expression on proliferation and migration of human melanoma A375 Cells. Cell Physiol Biochem 40(6): 1367-1376, 2016. PMID: 27997910. DOI: $10.1159 / 000453189$

7 Li Z, Ding S, Zhong Q, Li G, Zhang Y and Huang XC: Significance of MMP11 and P14(ARF) expressions in clinical outcomes of patients with laryngeal cancer. Int J Clin Exp Med 8(9): 15581-15590, 2015. PMID: 26629052.

8 Sementino E, Menges CW, Kadariya Y, Peri S, Xu J, Liu Z, Wilkes RG, Cai KQ, Rauscher FJ 3rd, Klein-Szanto AJ and Testa JR: Inactivation of Tp53 and Pten drives rapid development of pleural and peritoneal malignant mesotheliomas.
J Cell Physiol 233(11): 8952-8961, 2018. PMID: 29904909. DOI: $10.1002 /$ jcp. 26830

9 Supernat A, Lapinska-Szumczyk S, Majewska H, Gulczyński J, Biernat W, Wydra D and Zaczek AJ: Tumor heterogeneity at protein level as an independent prognostic factor in endometrial cancer. Transl Oncol 7(5): 613-619, 2014. PMID: 25048628. DOI: $10.1016 /$ j.tranon .2014 .06 .001

10 Han G, Sidhu D, Duggan MA, Arseneau J, Cesari M, Clement PB, Ewanowich CA, Kalloger SE and Köbel M: Reproducibility of histological cell type in high-grade endometrial carcinoma. Mod Pathol 26(12): 1594-1604, 2013. PMID: 23807777. DOI: 10.1038/modpathol.2013.102

11 Stoenescu VE, Niculescu M, Novac L, Manolea MM, Tomescu PI, Dijmărescu AL, Novac MB, Tudorache Ş and Iliescu DG: Immunohistochemical reaction of the glandular epithelium in endometrial hyperplasia compared to endometrial carcinoma. Rom J Morphol Embryol 58(3): 791-800, 2017. PMID: 29250656.

12 Bulsa $\mathrm{M}$ and Urasinska E: Triple negative endometrial cancer. Ginekol Pol 88(4): 212-214, 2017. PMID: 28509323. DOI: 10.5603/GP.a2017.0040

13 Gu F, Pfeiffer RM, Bhattacharjee S, Han SS, Taylor PR, Berndt S, Yang H, Sigurdson AJ, Toro J, Mirabello L, Greene MH, Freedman ND, Abnet CC, Dawsey SM, Hu N, Qiao YL, Ding $\mathrm{T}$, Brenner AV, Garcia-Closas M, Hayes R, Brinton LA, Lissowska J, Wentzensen N, Kratz C, Moore LE, Ziegler RG, Chow WH, Savage SA, Burdette L, Yeager M, Chanock SJ, Chatterjee N, Tucker MA, Goldstein AM and Yang XR: Common genetic variants in the $9 \mathrm{p} 21$ region and their associations with multiple tumours. Br J Cancer 108(6): 13781386, 2013. PMID: 23361049. DOI: 10.1038/bjc.2013.7

14 Guo C, Huang Y, Yu J, Liu L, Gong X, Huang M, Jiang C, Liao Y, Huang L, Yang G and Li J: The impacts of single nucleotide polymorphisms in genes of cell cycle and NF-kB pathways on the efficacy and acute toxicities of radiotherapy in patients with nasopharyngeal carcinoma. Oncotarget 8(15): 25334-25344, 2017. PMID: 28445979. DOI: 10.18632/oncotarget.15835

15 Jin L, Xu L, Song X, Wei Q, Sturgis EM and Li G: Genetic variation in MDM2 and p14ARF and susceptibility to salivary gland carcinoma. PLoS One 7(11): e49361, 2012. PMID: 23145162. DOI: 10.1371/journal.pone.0049361

16 Nascimento FP, Cardoso MG, Lindsey SC, Kunii IS, Valente FO, Kizys MM, Delcelo R, Camacho CP, Maciel RM and Dias-DaSilva MR: Analysis of somatic mutations in BRAF, CDKN2A/p16 and PI3KCA in patients with medullary thyroid carcinoma. Mol Med Rep 13(2): 1653-1660, 2016. PMID: 26718898. DOI: $10.3892 / \mathrm{mmr} .2015 .4731$

17 Song X, Sturgis EM, Huang Z, Li X, Li C, Wei Q and Li G: Potentially functional variants of p14ARF are associated with HPV-positive oropharyngeal cancer patients and survival after definitive chemoradiotherapy. Carcinogenesis 35(1): 62-68, 2014. PMID: 24104554. DOI: 10.1093/carcin/bgt336

18 Zhou X, Liao F, Zhang J, Qin Y, Xu H, Ding Z, Zhang Y and Zhang $\mathrm{F}$ : Association of the independent polymorphisms in CDKN2A with susceptibility of acute lymphoblastic leukemia. Biosci Rep 38(3), 2018. PMID: 29654170. DOI: 10.1042/BSR20180331

19 Zhang Y, Sturgis EM, Zafereo ME, Wei Q and Li G: p14ARF genetic polymorphisms and susceptibility to second primary malignancy in patients with index squamous cell carcinoma of the head and neck. Cancer 117(6): 1227-1235, 2011. PMID: 21381012. DOI: $10.1002 /$ cncr.25605 
20 Hungate EA, Vora SR, Gamazon ER, Moriyama T, Best T, Hulur I, Lee Y, Evans TJ, Ellinghaus E, Stanulla M, Rudant J, Orsi L, Clavel J, Milne E, Scott RJ, Pui CH, Cox NJ, Loh ML, Yang JJ, Skol AD and Onel K: A variant at 9p21.3 functionally implicates CDKN2B in paediatric B-cell precursor acute lymphoblastic leukaemia aetiology. Nat Commun 7: 10635, 2016. PMID: 26868379. DOI: $10.1038 /$ ncomms 10635

21 Sun P, Zhang Z, Wan J, Zhao N, Jin X and Xia Z: Association of genetic polymorphisms in GADD45A, MDM2, and p14 ARF with the risk of chronic benzene poisoning in a Chinese occupational population. Toxicol Appl Pharmacol 240(1): 66-72, 2009. PMID: 19596022. DOI: 10.1016/j.taap.2009.07.003

22 Wujcicka W, Zając A and Stachowiak G: Impact of MDM2, TP53 and P14ARF polymorphisms on endometrial cancer risk and onset. In Vivo 33(3): 917-924, 2019. PMID: 31028217. DOI: 10.21873/invivo.11559

23 Thakur N, Hussain S, Nasare V, Das BC, Basir SF and Bharadwaj M: Association analysis of p16 (CDKN2A) and RB1 polymorphisms with susceptibility to cervical cancer in Indian population. Mol Biol Rep 39(1): 407-414, 2012. PMID: 21567202. DOI: 10.1007/s11033-011-0752-Z

24 Yan L, Na W, Shan K, Xiao-Wei M, Wei G and Shu-Cheng C: p16(CDKN2) gene polymorphism: association with histologic subtypes of epithelial ovarian cancer in China. Int $\mathrm{J}$ Gynecol Cancer 18(1): 30-35, 2008. PMID: 17466040. DOI: 10.1111/j.1525-1438.2007.00953.x

25 SNPStats Software. Available at: https://www.snpstats.net/ start.htm [Last accessed 16/01/2020]

26 Saegusa M, Hashimura M, Suzuki E, Yoshida T and Kuwata T: Transcriptional up-regulation of Sox9 by NF-kappaB in endometrial carcinoma cells, modulating cell proliferation through alteration in the $\mathrm{p} 14(\mathrm{ARF}) / \mathrm{p} 53 / \mathrm{p} 21$ (WAF1) pathway. Am J Pathol 181(2): 684-692, 2012. PMID: 22698986. DOI: $10.1016 /$ j.ajpath .2012 .05 .008

27 Olcha P, Cybulski M, Skomra D, Obrzut B, Ignatov A, Jóźwik M, Schneider-Stock R and Semczuk A: The pattern of p14ARF expression in primary and metastatic human endometrial carcinomas: correlation with clinicopathological features and TP53 pathway alterations. Int J Gynecol Cancer 20(6): 993-999, 2010. PMID: 20683407. DOI: 10.1111/IGC.0b013e3181e76a4d

28 Maccioni L, Rachakonda PS, Bermejo JL, Planelles D, Requena C, Hemminki K, Nagore E and Kumar R: Variants at the 9p21 locus and melanoma risk. BMC Cancer 13: 325, 2013. PMID: 23816148. DOI: $10.1186 / 1471-2407-13-325$

29 Stenman G, Andersson MK and Andren Y: New tricks from an old oncogene: gene fusion and copy number alterations of MYB in human cancer. Cell Cycle 9(15): 2986-2995, 2010. PMID: 20647765. DOI: $10.4161 / \mathrm{cc} .9 .15 .12515$

30 Buas MF, Levine DM, Makar KW, Utsugi H, Onstad L, Li X, Galipeau PC, Shaheen NJ, Hardie LJ, Romero Y, Bernstein L, Gammon MD, Casson AG, Bird NC, Risch HA, Ye W, Liu G, Corley DA, Blount PL, Fitzgerald RC, Whiteman DC, Wu AH, Reid BJ and Vaughan TL: Integrative post-genome-wide association analysis of CDKN2A and TP53 SNPs and risk of esophageal adenocarcinoma. Carcinogenesis 35(12): 2740-2747, 2014. PMID: 25280564. DOI: 10.1093/carcin/bgu207
31 Sherborne AL, Hosking FJ, Prasad RB, Kumar R, Koehler R, Vijayakrishnan J, Papaemmanuil E, Bartram CR, Stanulla M, Schrappe M, Gast A, Dobbins SE, Ma Y, Sheridan E, Taylor M, Kinsey SE, Lightfoot T, Roman E, Irving JA, Allan JM, Moorman AV, Harrison CJ, Tomlinson IP, Richards S, Zimmermann M, Szalai C, Semsei AF, Erdelyi DJ, Krajinovic M, Sinnett D, Healy J, Gonzalez Neira A, Kawamata N, Ogawa S, Koeffler HP, Hemminki K, Greaves M and Houlston RS: Variation in CDKN2A at 9p21.3 influences childhood acute lymphoblastic leukemia risk. Nat Genet 42(6): 492-494, 2010. PMID: 20453839. DOI: 10.1038/ng.585

32 Gharbi H, Ben H, I, Soltani I, Safra I, Ouerhani S, Bel Haj Othmen H, Teber M, Farah A, Amouri H, Toumi NH, Abdennebi $S$, Abbes $S$ and Menif $S$ : Association of genetic variation in IKZF1, ARID5B, CDKN2A, and CEBPE with the risk of acute lymphoblastic leukemia in Tunisian children and their contribution to racial differences in leukemia incidence. Pediatr Hematol Oncol 33(3): 157-167, 2016. PMID: 27184773. DOI: 10.3109/08880018.2016.1161685

$33 \mathrm{Hu}$ WL, Li SJ, Liu DT, Wang Y, Niu SQ, Yang XC, Zhang Q, Yu SZ, Jin L and Wang XF: Genetic variants on chromosome 9p21 and ischemic stroke in Chinese. Brain Res Bull 79(6): 431435, 2009. PMID: 19559344. DOI: 10.1016/j.brainresbull. 2009.04.001

34 Yue X, Tian L, Fan X, Xu G, Shi FD and Liu X: Chromosome 9 p21.3 variants are associated with cerebral infarction in Chinese population. J Mol Neurosci 56(3): 546-552, 2015. PMID: 25665551. DOI: 10.1007/s12031-015-0494-9

35 Zajac A, Stachowiak G, Pertynski T, Romanowicz H, Wilczyński $\mathrm{J}$ and Smolarz B: Association between MDM2 SNP309 polymorphism and endometrial cancer risk in Polish women. Pol J Pathol 63(4): 278-283, 2012. PMID: 23359199. DOI: 10.5114/pjp.2012.32776

36 Zajac A, Stachowiak G, Smolarz B and Wilczyński JR: Polymorphisms of codon 72 of the TP53 gene in endometrial carcinoma of postmenopausal women. Postepy Hig Med Dosw (Online) 67: 1312-1318, 2013. PMID: 24379271. DOI: $10.5604 / 17322693.1080804$

37 Zajac A, Smolarz B, Stachowiak G and Wilczyński JR: TP53 and MDM2 polymorphisms and the risk of endometrial cancer in postmenopausal women. Med Oncol 31(11): 286, 2014. PMID: 25316267. DOI: $10.1007 / \mathrm{s} 12032-014-0286-\mathrm{Z}$
Received December 28, 2019

Revised January 14, 2020

Accepted January 16, 2020 